\title{
DENITRIFICATION OF GROUNDWATER USING GRAPHENE, GRAPHENE OXIDE AND NANOCOMPOSITES
}

\author{
Bhagyeshwari D Chalageri $^{1}$, Archna $^{2}$, Rajeswari M Kulkarni ${ }^{3}$ \\ ${ }^{1}$ Department of Chemical Engineering, M S Ramaiah Institute Of Technology, Bengaluru-560054 Karanataka, India \\ ${ }^{2}$ Department of Chemical Engineering, M S Ramaiah Institute Of Technology, Bengaluru-560054 Karanataka, India. \\ ${ }^{3}$ Department of Chemical Engineering, M S Ramaiah Institute Of Technology, Bengaluru-560054 Karanataka, India.
}

\begin{abstract}
Pollution of air, soil and water is a global concern for the human society and their environment. Removal of these pollutants from the environment is a huge challenge. Compared to other techniques adsorption techniques are more effective and simple in the removal of contaminants and depend on their pore and surface properties. New size based physiochemical properties formulate nanoparticles with huge range of applications in biomedical, sensors, electronic devices catalyst, membranes removing environmental pollutants and so on. New carbonaceous nanomaterials graphene and graphene oxide which has large high surface area and functional groups signifying their prospective for the adsorption processes. In this review paper, we highlight few current advances in graphene and graphene oxide nanocomposites for the removal of nitrate from water. Nanocomposites material enhances adsorption capacity as well separation efficiency by modifying graphene or else graphene oxide. To increase the adsorption rate by activation of graphene and graphene oxide using nanocomposites will be a promising way for further research in denitrification of groundwater.
\end{abstract}

Keywords: Graphene, Graphene oxide, Nanocomposites

\section{INTRODUCTION}

Nitrogen, an essential element, forms an integral component in living organism in its molecular or ionic forms and its biological mediated pathways include symbiotic fixation, plant uptake, ammonification, immobilization of nitrate, nitrification, denitrification, leaching and through volatization into the atmosphere as ammonia, nitrous oxide and gaseous nitrogen (Archna et al 2012). Industrialization, growing food and energy demand have lead to anthropogenic emissions of nitrogen compounds at alarming rates ever than before. The nitrogen spread through water and air as a resultant of excessive use of fertilizers, domestic water lechates, municipal waste treatment plant effluents have entered ground water aquifers (Anderson et al 2014, Loganathan et al 2012, Shrimali et al 2001).

Prominent levels of nitrate in potable water can cause many health problems like stomach cancer, methehemoglobinemia (blue baby syndrome), diabetes, other infectious diseases in humans. Conversion of nitrate to nitrite, causes serious health risk by reacting with hemoglobin to cause (cyanosis) bluish discoloration of the skin in newborn infants due to inadequate oxygenation of the blood (Archna et al 2012).

In cattle's, and some other domestic animals acute poisoning can take place within 4hours after ingestion of plants or high concentration of nitrate through water. According to EPA and WHO guidelines, the maximum allowable nitrate concentration is $50 \mathrm{mg} / \mathrm{L}$ by nitrate and $10 \mathrm{mg} / \mathrm{L}$ by nitrogen, accepted as safe for public water system (Fataei et al 2014).
Recently, using nanotechnology some important pollutants like nitrate are being removed from water resources (Roco et al 2010). Use of nanofilters is the newest method to treat and eliminate water pollutants (Bhattacharya et al 2013) and are known to have a higher potential in converting nitrate to nitrite (Fataei et al 2014, Sharma et al 2009).

Graphene is a miraculous, the world's first two-dimensional (2D) material and latest addition to the carbon family that has attracted attention. Graphene, hottest nano-material in nanotechnology has fascinated the scientific research community by its diverse novel properties (Geim et al 2008). Graphene symbolize, a theoretically novel class of material that is only one atom thick with $2 \mathrm{D}$ layer of hybridized $\mathrm{sp}^{2}$ carbon, offers novel inroads into research that has never ceased to astonish and continues to offer a fertile ground for applications (Huang et al 2012).

Several properties of graphene like chemical, mechanical and electronic make it functional for fabricating nanocomposites materials. Being 200 times stronger than steel, tensile strength of the nanocomposites material can be increased by doping metals and plastics by graphene (Novoselov et al 2004, 2012).

\section{REMOVAL OF WATER POLLUTANTS USING NANOTECHNOLOGY}

Recently, availability of clean water is a major issue and it is quite difficult to solve due to the associated problems. Only $30 \%$ of total volume of water available on earth is available for human consumption. The other $70 \%$ are trapped in the 
glaciers or is in the form of ice and out of the available $30 \%$, only $0.08 \%$ of it is completely clean (Krantzberg et al 2010, Wang et al 2013). Groundwater, surface water and waste water are polluted by various sources such as waste disposed, leaked fertilizers, herbicides, oil spills, byproducts of processes and combustion, pesticides, fossil fuels extraction etc.(Sharma et al 2009, Liu et al 2012).

To remove these dissolved impurities, various processes such as reverse osmosis, ultra filtration, nano filtration, solar desalination etc have been used and they have shown high adsorption capacity in removal of some of the important pollutants like organic compounds, heavy metal cations and anions (Upadhyayula et al 2009, Foo et al 2010). These advanced methods use of nano-materials made of activated carbon, carbon tubes, graphene and graphene oxide carbon nanotubes, biopolymers, single-enzyme nanoparticles, self assembled monolayer on mesoporous support system, zeolites, nanoparticles of zero valent iron are used for water remediation (Liu et al 2012) with enhanced affinity, capacity, selectivity for heavy metals and other contaminants. Higher reactivity, larger surface contact and better disposal capability are the advantages of using nanomaterials in the removal of water pollutants (Wang et al 2013, Sharma et al 2009).

\section{GRAPHENE}

Graphene the newly isolated allotrope of carbon, is a single, tightly packed pure layer of carbon atoms collectively bounded in a hexagonal honeycomb lattice that provides rich lode of novel, fundamental and practical applications (Geim et al 2008, Novoselov et al 2004). Graphite and graphene share the exactly similar basic structural array of their constituent carbon atoms. Each structure begins with six atoms of carbon that are tightly bound chemically together to form a regular hexagon- like benzene ring(Gollavelli et al 2013). In otherwords, graphene is an allotrope of carbon in the structure of plane of $\mathrm{sp}^{2}$ bonded atoms with molecule bond length of $0.142 \mathrm{~nm}$. Layers of graphene stacked on top of each other form graphite, with an interplanar spacing of $0.335 \mathrm{~nm}$ (Huang et al 2012, Novoselov et al 2012).

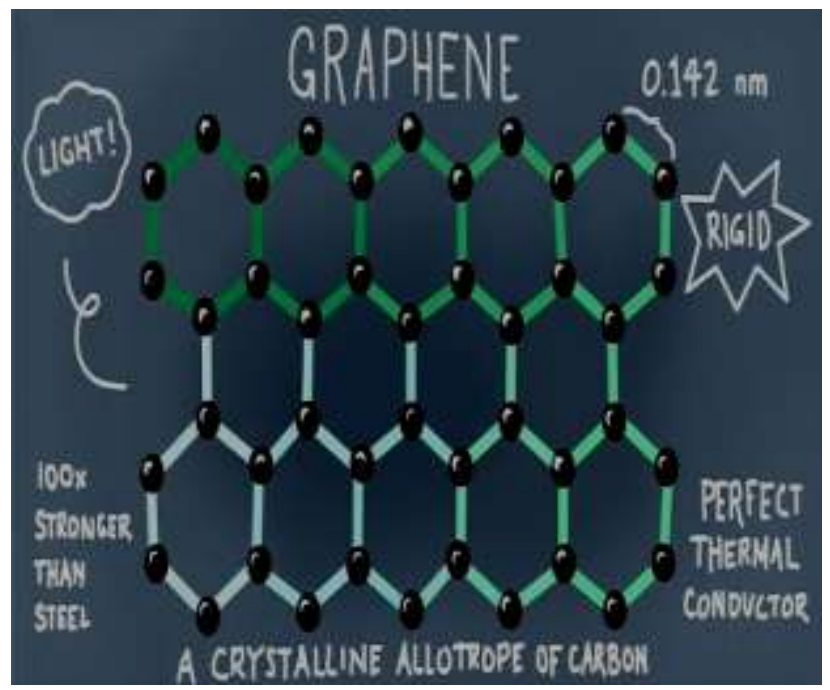

Fig 1: Structure of graphene ( aerographene.com)

\section{EXCEPTIONAL FEATURES OF GRAPHENE}

Graphene, the thinnest material discovered (1 million times thinner than human hair possible on earth), lightest material known (1 square meter: $0.77 \mathrm{mg}$ ), transparent ( 200 times stronger than steel), incredibly flexible, best conductor of heat and electricity, all due to the combination of purity and orderliness of the arranged carbon atoms (Geim et al 2008, Novoselov et al 2004). Perfect crystalline order arises from the strong and extremely flexible interatomic bonds. This creates a substance harder than diamond yet allows the planes to bend whenever mechanical forces are applied. The quality of crystal lattice is also responsible for graphene's remarkable high electrical conductivity (Geim et al 2008, Novoselov et al 2012).

Graphene has an ultra-large specific-surface area of 2630 $\mathrm{m}^{2} / \mathrm{g}^{-1}$ which is an unique feature when compared to other allotropes of carbon (Krantzber et al 2012). The exceptional conduction of electrons, moving unimpeded through the lattice at a faster rate attributes the properties of graphene (Geim et al 2008, Novoselov et al 2004) such as high electron mobility, high opacity due to an one-atom thick fabric of carbon, mechanical strength, exceptionally high electronic and thermal conductivity, impermeability to gases and other supreme properties, all of which is making it a next-generation nano-materials tht can be applied as nanocomposites, nanoelectronics, , nanosensors and nanodevices (Huang et al 2011, Novoselov et al 2012, Young et al 2012).

Carbon, the second most abundant mass within the human body and fourth in the order of most abundant element by mass, followed by hydrogen, helium and oxygen (Geim et al 2008 ) is the chemical basis for all known life forms on universe, and hence graphene could be a sustainable, ecologically friendly solution to an infinite number of applications (Young et al 2012). Graphene, since founded, has been applied in various scientific disciplines, with enormous gains being made particularly in chemical, biotechnology and electronics.

\section{GRAPHENE OXIDE- AN OXIDIZED} PRODUCT OF GRAPHITE

Graphene oxide is functionalized grapheme containing oxygen and chemical groups. It has attracted research interests in recent years due to its superior properties such as surface area, mechanical stability, optical and electrical properties (Dreyer et al. 2009). The surface functional groups of hydroxyl, carboxyl and epoxy make graphene oxide an excellent material when combined with other materials and molecules (Liu et al. 2012).

Functional groups of graphene oxide exhibit strong acidity, high adsorptivity for basic compounds and cations. Graphene provides hydrophobic surface, superior mechanical properties that exhibit high adsorption due to strong $\pi-\pi$ interaction. Graphene possesses superior mechanical properties than graphene oxide, but they both 
provide equal levels of stiffness and strength (Young et al 2012). These new carbonaceous materials, effectively adsorb diverse gaseous and aqueous pollutants (Wang et al 2013)providing a promising arena that promotes nitrate removal from water (Motamedi et al 2014).

Table 1: Maximum adsorption capacity of various absorbents of nitrate

\begin{tabular}{|l|l|l|l|}
\hline Adsorbent & $\begin{array}{l}\text { Amount of } \\
\text { Nitrate } \\
\text { Absorbed } \\
(\mathbf{m g} / \mathbf{g})\end{array}$ & $\begin{array}{l}\text { Specific } \\
\text { Area } \\
\left(\mathbf{m}^{2} / \mathbf{g}\right)\end{array}$ & Reference \\
\hline $\begin{array}{l}\text { Magnesium } \\
\text { Oxide-Biochar }\end{array}$ & 94 & & $\begin{array}{l}\text { Zhang et al } \\
2012\end{array}$ \\
\hline $\begin{array}{l}\text { Acid Treated } \\
\text { Sepiolite }\end{array}$ & 38 & 515 & $\begin{array}{l}\text { Ozturk et al } \\
2004\end{array}$ \\
\hline $\begin{array}{l}\text { HCl Treated } \\
\text { Red Mud }\end{array}$ & 363 & 20.7 & $\begin{array}{l}\text { Cengeloglu } \text { et } \\
\text { al 2006 }\end{array}$ \\
\hline $\begin{array}{l}\text { Activated } \\
\text { Carbon Cloth } \\
\text { (H2SO4) }\end{array}$ & 126 & 2500 & $\begin{array}{l}\text { Afkhami } \text { et al } \\
2007\end{array}$ \\
\hline $\begin{array}{l}\text { Protonated } \\
\text { Cross-linked } \\
\text { Chitosan }\end{array}$ & 104 & - & $\begin{array}{l}\text { Chatterjee } \text { et } \\
\text { al 2009 }\end{array}$ \\
\hline $\begin{array}{l}\text { ZnCl } \text { Treated } \\
\text { Coconut Coir } \\
\text { Pith }\end{array}$ & 10.3 & 910 & $\begin{array}{l}\text { Namasivaya } \\
\text { m 2005, 2008 }\end{array}$ \\
\hline $\begin{array}{l}\text { ZnCl } \text { Treated } \\
\text { Activated } \\
\text { Carbon }\end{array}$ & 27.6 & 1826 & $\begin{array}{l}\text { Demiral } \text { et al } \\
2010\end{array}$ \\
\hline $\begin{array}{l}\text { Zirconium } \\
\text { Oxychloride- } \\
\text { Sugar Beet Pulp }\end{array}$ & 63 & - & $\begin{array}{l}\text { Hassan } \text { et al } \\
2010\end{array}$ \\
\hline
\end{tabular}

\section{REMOVAL OF NITRATE USING GRAPHENE} NANOCOMPOSITES

In recent past, graphene, graphene oxide and their altered forms can be applied as good materials for nitrate removal.

Catalyst such as palladium-copper held by graphene with $\mathrm{Fe}^{0}$ reductants showed $82 \%$ of nitrate removal and $66 \%$ of N2 selectvity (Yun et al 2016).

Magnetic graphene nanoparticles (G-Fe3O4 MNPs) using Taguchi experimental design and parameters were optimized batch reactor by Minitab software. The results revealed that in optimized condition ( $\mathrm{pH}-3$, contact time-60min, initial concentration-50mg/L, ,temperature- $50^{\circ} \mathrm{C}$, adsorbent dosage- $2 \mathrm{~g} / \mathrm{L}$ ) $86.4 \%$ of nitrate removal was achieved. G$\mathrm{Fe} 3 \mathrm{O} 4$ Magnetic nanoparticles is an effective sorbent for removal of nitrate from water because of its easy, rapid and high nitrate removal efficiency (Ghanizadeh et al 2015).

Nanocomposites material nano-scale zero valent iron, activated carbon can remove nitrate up to $94.3 \%$. Nanocomposites material showed high efficiency in removal of nitrate compared to nanoscale zero valent iron (Liu et al 2016).
Nitrate removal from water can be achieved by coating nickel and cobalt nanoparticles with graphene oxide. Iron, nickel and cobalt with novel and unique properties of graphene based nanocomposites which showed outstanding performance in nitrate removal from water (Motamedi et al 2014).

\section{CONCLUSION}

Graphene is one of the highly potential materials which have led to a cascade of diverse international research and infinite technologies especially in water purification technology.

Practicability of using graphene, graphene oxide and nanocomposites is enormous in denitrification of groundwater due to exceptional properties including and also ultra large specific-surface area which contributes largely in enhancing the adsorption capacity in removal of nitrate from groundwater.

\section{ACKNOWLEDGEMENT}

We wish to acknowledge Department of Chemical Engineering, M S Ramaiah Institute of Technlogy, Bengaluru for all the support extended.

\section{REFERENCES}

[1] Anderson T R, Groffman P M, Sujay S K and Walter M T (2014) "Shallow Groundwater Denitrification in Riparian Zones of a Headwater Agricultural Landscape" Journal of Environmental Quality, 43: 732-744.

[2] Archna, Sharma Surinder $K$ and Sobti Ranbir Chander (2012) "Nitrate Removal from Ground Water: A Review" E-Journal of Chemistry, 9(4): 1667-1675.

[3] Archna and Pinto P C (2014) “ Biological Denitrification of Ground water Contaminated by Leachate from Landfills" The International Reviewer, 1(1): 9-11.

[4] Afkhami A, Madrakian T, Karimi Z (2007) “ The Effect of Acid Treatment of Carbon Cloth on the adsorption of Nitrite and Nitrate Ions" Journal of Hazardous Materials, 144: 427-431.

[5] Babel S, Kurniawan T A (2003) "Low-Cost Adsorbents for Heavy Metals Uptake from Contaminated Water: A Review" Journal of Hazardous Materials, 97: 219-243.

[6] $\quad \mathrm{xxZz}$

[7] Bhattacharya Sayan, Saha Indranil, Mukhopadhayay Aniruddha, Chattopadhyay Dhrubajyoti, Ghosh Uday Chand and Chatterjee Debashis (2013) "Role of Nanotechnology in Water Treatment and Purification: Potential Applications and Implications" International Journal of Chemical Science and Technology, 3(3): 59-64.

[8] Cengeloglu Y, Tor A, Ersoz M, Arslan G (2006) "Removal of Nitrate from Aqueous Solution by using Red Mud” Purification Technology, 51: 374-378. 
[9] Chatterjee S, Lee D S, Lee M W, Woo S H (2009) "Nitrate Removal from Aqueous Solution by CrossLinked Chitosan Beads Conditioned with Sodium Bisulfate" Journal of Hazardous Materials, 166: 508513.

[10] Dabrowski A, Podkoscielny P, Hubicki Z, Barczak M(2010) "Adsorption of Phenolic Compounds by Activated Carbon - A Critical Review" Chemosphere, 58: 1049-1070.

[11] Demiral H, Gündüzo Glu G (2010) “ Removal of Nitrate from Aqueous Solutions by Activated Carbon Prepared from Sugar Beet Bagasse" Bioresource. Technology. 101,1675-1680.

[12] Dreyer Daniel R, Park Sungjin, Bielawski Christopher W and Ruoff Rodney S (2009) "The Chemistry of Graphene Oxide" Chemical Society Reviews, 39: 228-240.

[13] Fataei E, Shariff A S, Kourandeh H H P, Sharifi A S, Safavyan S T S (2013) "Nitrate Removal from Drinking Water in Laboratory-Scale using Iron and Sand Nanoparticles" International Journal of Biosciences, 3(10): 256-261

[14] Foo K.Y and Hameed B.H(2010) "Detoxification of pesticide waste via activated carbon adsorption process" Journal of Hazardous Materials, 175: 1-11.

[15] Geim A K and Novoselov K S (2007) "The Rise of Graphene" Nature Materials, 6:183-191.

[16] Ghanizadeh G, Azari A, Akbari H, Rezaei Kalantary $R$ (2015) “ Performance Evaluation of Nanocomposite Magnetic Graphene Sheet- Iron Oxide in Removal of Nitrate from Water Using Taguchi Experimental Design" J Mazandaran Univ Med Sci,25(127):49-64.

[17] Gollavelli Ganesh, Chang Chun-chao, Ling YongChien (2013) "Facile Synthesis of Smart Magnetic Graphene for Safe Drinking water: Heavy Metal Removal and Disinfection" ACS Sustainable Chemical Engineering, 1:462-472.

[18] Guo Juan, Wang Ruiyu, Tjiu Weei Weng, Pan Jishenga, Liu Tianxi (2012), "Synthesis of Fe Nanoparticles@Graphene_Composites for Environmental Applications" Journal of Hazardous Materials, 225:63-73.

[19] Hassan M L, Kassem N F, El-Kader A H A (2010) “ Novel Zr(IV) Sugar Beet Pulp Composite for Removal of Sulphate and Nitrate Anions" Journal Application Polymer Sci, 117: 2205-2212.

[20] Huang X, Yin Z, Wu S, Qi X, He Q, Zhang Q, Yan Q, Boey F, Zhang H (2011) "Graphene-Based Materials :Synthesis, Characterization, Properties and Applications" EPub 7(14):1876-1902.

[21] Huang X, Qi X, Boey F, Zhang H (2012) "Graphene Based Composites” Chem. Soc Rev, 41(2): 666-686.

[22] Ji Min-Kyu, Ahn Yong-Tae, Khan Moonis Ali, AbouShanab Reda A I, Cho Yunchui, Choi Jae-Young, Kim Yong Je, Song Hocheol, Jeon Byong-Hun (2011) "Removal of Nitrate and Ammonium Ions from Livestock Wastewater by Hybrid Systems Composed of Zero-Valent Iron and Adsorbents"
Journal of Environmental Technology, 32(16):18511857.

[23] Joshi R K, Carbone P, Wang F C, Kravets V G, Su Y, Grigorieva I V, Wu H A, Geim A K, Nair R R (2014) “Precise and Ultrafast Molecular Sieving Through Graphene Oxide" Science, 343(6172): 752-754.

[24] Khani A and Mirzaei M (2008) "Comparative Study of Nitrate Removal from Aqueous Solution using Powder Activated Carbon Nanotubes" $2^{\text {nd }}$ Intl IUPAC Conf on Green Chemistry.

[25] Krantzber G, Tanik A, do Carmo, Indarto A and Ekda (2010) "Advances in water quality control" Scientific Research Publishing

[26] Liu Fei, Chung Soyi, Oh Gahee, Seo Tae Seok (2012) "Three-Dimensional Graphene Oxide Nanostructure for Fast and Efficient Water-Soluble Dye Removal" ACS Applied Material Interfaces, 4:922-927.

[27] Liu Guo, Zhou Yaqi, Liu Zhaoyang, Zhang Junjie, Tang Binbin, Yang Shaogui, Sun Cheng (2016) "Efficient Nitrate Removal Using Micro-electrolysis with Zero Valent Iron/Activated Carbon Nanocomposite" Journal of Chemical Technology and Biotechnology.

[28] Loganathan Paripurnanda, Vigneswaran Saravanamuthu, Kandasamy Jaya (2012) “ Enhanced Removal of Nitrate from Water using Surface Modification of Adsorbents: A Review" Journal of Environmental Management. 131: 363-374.

[29] Mohan D and Pittman C.U(2006) "Activated Carbons and Low Cost Adsorbents for Remediation of Tri- and Hexavalent Chromium from Water" Journal of Hazardous Materials, 137: 762-811.

[30] Motamedi E, Talebi Atouei M, Kassaee M Z (2014) "Comparision of Nitrate Removal from Water via Graphene Oxide Coated $\mathrm{Fe}, \mathrm{Ni}$ and $\mathrm{Co}$ Nanocomposites" Materials Research Bulletin, 54: 34-40.

[31] Nair R R, Wu H A, Jayaram P N, Grigorieva I V, Geim A K (2012) "Unimpeded Permeation of Water Through Helium-Leak-Tight Graphene-Based Membranes" Science, 335(6067):442-444.

[32] Namasivayam C, Sangeetha D (2005) "Removal of Nitrate from Water by $\mathrm{ZnCl} 2$ Activated Carbon from Coconut Coir Pith, An Agricultural Solid Waste" Indian Journal of Chemical Technology, 12: 513-521.

[33] Namasivayam C, Sangeetha D (2008) "Application of Coconut Coir Pith for the Removal of Sulphate and Other Anions from Water. Desalination 219: 1-13.

[34] Novoselov K S, Geim A K, Morozov S V, Jiang D, Zhang Y, Dubonos S V, Grigorieva I V, Firsov A A (2004) "Electric Field Effect in Atomically Thin Carbon Films" Science,306:666-669.

[35] Novoselov K S, Fal'ko V I, Colombo L, Gellert P R, Schwab M G and Kim K (2012) "A Roadmap for Graphene" Nature, 490(7419):192-200.

[36] Ozturk N, Bektas T E (2004) "Nitrate Removal from Aqueous Solution by Adsorption onto Various Materials" Journal of Hazardous Materials, B112: 155-162. 
[37] Roco M C, Williams S and Alivisators P (2010) "Nanotechnology Research Directions: Vision for Nanotechnology in the Next Decade,"Washington, DC: IWGN Workshop Report, U S National Science and Technology Council.

[38] Sharma Y .C, Srivastva V, Singh V. K, Kaul S N, and Weng C H(2009) " Nano-Adsorbents for the Removal of Metallic Pollutants from Water and Waste water," Environmental Technology, 30:583609.

[39] Shrimali M, Singh K P (2001) "New Methods of Nitrate Removal from Water" Environmental Pollution, 112:351-359.

[40] Sohn K, Kang S W, Ahn S, Woo M, Yang S K (2006) "Fe(0) Nanoparticles for Nitrate Reduction: Stability, Reactivity and Transformation" Environment Science and Technology. 40: 5514-5519.

[41] Sreeprasad T S, Maliyekkal M Shihabudheen, Lisha K P and Pradeep T (2010) "Reduced Graphene Oxide -Metal /Metal Oxide Composites: Facile Synthesis and Application in Water Purification" Journal of Hazardous Materials.

[42] Upadhyayula V.K.K, Deng S, Mitchell M.C, Smith G.B (2009) "Application of Carbon Nanotube Technology for Removal of Contaminants in Drinking Water: A Review," Science Total Environment, 408: 1-13.

[43] Wang Shaobin, Sun Hongqi, Ang H M and Tade M $\mathrm{O}(2013)$ "Adsorptive Remediation of Environment Pollutants using Novel Graphene -Based Nanomaterials" Chemical Engineering Journal, 226: 336-347.

[44] Young Robert J, Kinloch Ian A, Gong Lei, Novoselov Kostya S (2012) "The Mechanics of Graphene Nanocomposites: A Review" Journal of Composites Science and Technology, 72(12):1459-1476.

[45] Yun Yupan, Li Zifu, Chen Yi-Hung, Saino Mayiani, Cheng Shikun, Zheng Lei (2016) "Reduction of Nitrate in Secondary Effluent of Wastewater Treatment Plants by $\mathrm{Fe}^{0}$ Reductant and Pd$\mathrm{Cu}$ /Graphene Catalyst" Water, Air and Soil Pollution, 227:111.

[46] Zhang M, Gao B, Yao Y, Xue Y, Inyang M (2012) "Synthesis of Porous MgO Bichar Nanocomposites for Removal of Phosphate and Nitrate from Aqueous Solutions" Chemical Engineering Journal, 210: 2632.

[47] Zhang Yifeng and Angelidaki Irini (2013) “A New Method for In-Situ Nitrate Removal from Groundwater using Submerged Microbial Desalination- Denitrification Cell (SMDDC)" Water Research, 47:1827-1836. 